PNEUMOTHORAX, WITH AUTOPSY, IN A SUBJECT WITH EXTREME RETRO-LATERAL CURVATURE OF THE SPINE.

BY HORACE E. MARION, M.D.

MARCH 28, 1886, I was called to see C. A. N., a clerk, age forty-three. He has angular postero-lateral curvature of the spine, supposed to be from injury in infancy.

On the 24th (four days before), while at work at his desk, and after partaking of a moderate lunch, he was attacked with a severe pain piercing his right lung. (The curvature has its convexity to the right.) He got up, moved about the office, and after a short time resumed his work. On retiring that night he felt chilly, but made but little account of it: indeed, he went to town next day, and worked at City Hall all day. The day following he remained at home, but on Saturday (27th) he worked all day, and in the evening attended a Masonic meeting.

I found him (28th) sitting in the bed, suffering from such severe pain that he was unable to lie down. Pulse 90 to 100 , temperature $101^{\circ}$. No cough, hurried and shallow respiration. Flatness at base of right lung (the chest is so elongated antero-posteriorly that the dulness may have been natural). The chest is extremely asymmetrical. Friction-murmurs in axillary line, about the six th rib.

April 5th. 'Temperature and pulse have remained about the same, with relief to the severe pain. Pulse 90 to 100 , temperature $99^{\circ}$ to $100^{\circ}$. Friction-murmur has been very distinct along the fifth and sixth ribs. Yesterday, that is, a little more than ten days from the first symptoms of pain, while drinking milk, some went, as he said, the "wrong way," causing him to strangle, cough, and vomit. 'To-day, examination shows tympanitic resonance over the greater portion of the right chest, metallic tinkling, amphoric respiration and voice, with also succussion-sound. Much distressed after lying in one position for any length of time, or after sleeping.

April 7th. No special change. Friction-murmur can still be heard. Severe pain after sleeping, or in attempting to change position, extending to back and shoulder. Pulse 90 to 110 , temperature $99^{\circ}$ to $102^{\circ}$.

April 8th. Dr. F. I. Knight saw him in consultation. He found pleuritic friction, effusion, and air within the chest; as he expressed it, an unusual combination in acute pleurisy, and one not easily accounted for.

April 12th. Fair night, but complains of pain in back, that his back is broken in two; somewhat delirious. Respiration 44, face puffy, skin moist and slightly cyanotic. Aspirated, removing three and one half pints of offensive pus; during the escape of the last half pint, air escaped through the tube with considerable force.

April 13th. Had a comfortable night after 12 o'clock. An hour after aspiration he had a chill, and his temperature reached $104^{\circ}$, followed by profuse perspiration. Has no pain, and feels much better. Amphoric breathing and metallic tinkling.

April 16th. No special change, except that now he tastes the offensive pus when he coughs. The odor is noticeable in the room.

April 17th. Made a permanent opening, removing about three pints of extremely offensive pus. In-

1 Read before the Boston Society for Medical Observation, December $\delta, 1887$. serted drainage-tube, and dressed with bichloride gauze.

April 18th. Washed out the chest with solution bichloride, 1 to 3,000 , and dressed with antiseptic gauze. April 27 th. Since the permanent opening the temperature has been but once above $99^{\circ}$, most of the time $982^{\circ}$. The pulse has remained frequent, about 100. Respiration from 30 to 35 in the minute. Removed the tube.

May 29th. Still discharging; can easily introduce bougie within the chest. Respiration good in front and back: flatness below the level of the opening. Coughs a good deal. During the past mouth the temperature has ranged from $982^{\circ}$ to $100^{\circ}$. Pulse and respiration always accelerated.

June 1st. Has been out when the weather was fine. June 7 th. Opened an abscess below and in front of the original opening, with which it is connected.

June 13 th. His condition not improving satisfactorily, and after counsel, gave ether and enlarged the opening into the chest. No pus was found. Drainage-tube left in situ.

June 15 th. Pulse 120 , temperature $104^{\circ}$, respiration 30 . Some pain on sneezing, taking a long breath, and in gaping. Coughs, and raises offensive matter on rising in the morning. No appetite. Almost no discharge from the side.

June 21st. For the first time, seems to feel better ; temperature and pulse normal. No discharge.

June 23d. No discharge. 'Tube left out. Still expectorates offensive pus. A few râles, moderately coarse, can be heard just beneath the clavicle.

June 26th. Considerable offensive discharge from the sinus.

June 28th. Still discharging large quantities of offensive pus from the side. Washed out the chest and re-introduced the tube.

July 18th. Still coughs a little, and expectorates a little purulent matter in the morning. 'Tube out. Can easily pass bougie into the chest.

From this date he improved constantly, though slowly, until quite recovered, so as to resume his work about the middle of September. 'The opening in his side did not close until about the first of October.

From this time until June 1, 1887, I saw him frequently, but not professionally. His widow informs me that: He was able to attend to his regular duties at City Hall all the time ; that he was quite well during the winter. In January he suffered from "teethache," for which he consulted a dentist and had some teeth extracted, with no relief to pain. Many of the teeth became loosened, but did not decuy. Complained of severe pain of his right shoulder and back at times. In February, the wound in his side reopened and discharged a little thin, sero-purulent matter, and remained open ever after, except during July and a part of August.

In April and May, had an attack of what passed as dyspepsia. He was thought to have lost flesh and strength ever after February, when the wound reopened. About this time, he began to have nightsweats more or less constantly. His cough was slight, never troublesome, but he never was a long time without some cough, although he made no account of it.

June 1, 1887. I was again called to see Mr. N., on account of a painful swelling just below knee and to the inner side of leg. He was at his desk, writing; 
said it caused no pain unless he moved the leg. The about three-fourths larger than the right. 'The left irregular, cord-like feel, its depth, and the cellular lung was vicariously enlarged and free from disease. tissue not being involved, suggested phlebitis. He The right lung correspondingly small was bound to was urged to take his bed, and a bandage was applied. the lateral aspect of the chest wall by a firm band

June 6th. He took his bed three days ago. Obliged which completely enclosed a pus cavity about four by to keep the leg in one position; cellular tissue becom- six inches in size. Lung tissue, except for about an ing involved.

Physical examination of lung gives no new evidence. Fistulous track to what seems to be a circumscribed pleural cavity, still open. No cough to speak of.

August 20th. Since last notes, now more than a month, he has remained in bed all the time. For the first three weeks in June he did his writing (clerk for the assessors) in bed. Has lost flesh and strength. Temperature scarcely ever above $100^{\circ}$. Pulse 100 to 110.

Three pyæmic abscesses have been opened; namely, one below and one above the right knee and one on anterior part of left leg. Another over and just above the left trochanter should have been, but he would not allow it. Complains frequently of intense pain in right shoulder and in the back, which he says is breaking-in-two.

For past three weeks at least, has remained with his right thigh flexed in the pelvis. For past five weeks the opening into the chest has been closed or healed. Has had scarcely any cough until last night, when he coughed up a third of a teacup of offensive pus.

After a great deal of coaxing, I opened a fluctuating tumor just to the right of the fourth lumbar vertebra. About a pint of offensive pus was evacuated, and a drainage-tube introduced, extending along the crest of the ilium to its anterior spinous process.

September 4th. He consented to-day to have the tumor over the trochanter aspirated: one-half pint of matter was removed. Gradually losing ground.

October 17th. Has failed more rapidly lately. To move him has caused excruciating pain. For days past his death has seemed imminent.

'This morning, not having syringed out the pus cavities for the past two mornings on account of his extreme weakness, I got him up on the side of the bed as usual and commenced; the first water thrown into the opening low down in the back seemed to strangle him and I desisted. I got him back into the bed bolstered up with pillows, but he died within an hour.

Autopsy, twenty-four hours after death. Right postero-lateral curvature of spine. Emaciation extreme. Rigor mortis marked. Right thigh flexed at an angle of $50^{\circ}$, with horizontal plane of body. 'Thin pus exuded from an opening just above right knee, at iuner side of right calf, over middle and front of left tibid, over left trochanter, on a level with and to the right of fourth lumbar vertebra and at angle of right scapular. The curvature is such that the right scapular rests apparently upon the top of right chest. Over the angle of the curvature is an enormous bedsore fully six inches in diameter, in which are exposed muscles, faciæ and bone.

On removing the sternum and costal cartilages the left lung collapsed. The heart, a little further to the left than normal, was normal in size and general appearance. The pericardium contained about forty grammes of serum. Heart substance firm and valves normal. The coronary arteries much enlarged and atheromatous; atheromatous changes had also taken place in the aorta. The left thoracic cavity was

Nothing remarkable about the stomach, intestines or bladder. Spleen much enlarged, soft and friable. Left kidney twice the size of right, capsules easily removed, hyperæmic, but otherwise normal save at the upper convex border of the right, where small pus cavities had begun to form.

Liver was in size normal, but somewhat fatty. At the greater extremity or border, a change similar to that of the kidney had taken place. The necrosis of the liver and kidney was immediately in contact with a pus channel, to be described. Removing all the organs, it was easy to demonstrate a sort of covered way extending along the chest wall down wards, in wards, and backwards, from the opening between the eighth and ninth ribs at angle of scapulæ to the angle of the curvature and to the bottom of pus-cavity. The angle of curvature was one of about $25^{\circ}$ or $30^{\circ}$. The inflammatory tissue could be easily removed, leaving bare the vertebræ at the angle of curvature, exposing also the aorta in its course, which, by the way, passing over the convexity of the angle, lay within less than an inch from the opening into the chest.

This pus-channel continued along the vertebræ behind the liver and kidney, as before alluded to, to the right iliac fossa as far as Poupart's ligament, and backwards to middle of sacrum. The opening near the fourth lumbar vertebra communicated with the iliac fossa along the crest of the ilium. The inner aspect of the ilium was entirely denuded of periosteum, as was a portion of the sacrum.

I have reported the foregoing case inasmuch as it presented a few points of interest. I have designated it a case of pyo-pneumothorax, although I am not sure that at first it was not a case of hydro-pneumothorax. In both, the physical signs would be quite similar.

The sequence of events was as follows: Acute pleuritis, not wholly incapacitating the patient for work, followed by an effusion within four days, or prior to my first visit. One week later, or two days from the initial pain, there was positive evidence of air within the pleural cavity. Air was detected soon after his severe fit of coughing and strangling.

On aspirating the chest one week later, or seventeen days from the initial pain, the fluid proved to be purulent and offensive.

I would remark here that the deformity rendered it impossible to say exactly whether the heart was in or out of its normal position, and to fix definitely the line of fluid dulness. Five days after aspirating, or twentytwo from the attack, the permauent opening was made, with marked improvement to all his symptoms.

In ten days after introducing the tube it was removed, as everything had been absolutely dry for several days. This was thirty-two days from the attack. In thirty-four more days, or sixty-six from the attack, the opening was enlarged and tube left in situ, although the cavity contained no pus. In ten days more the tube was left out. but re-introduced at the end of five days, and soon discontinued altogether. For three months longer, or one hundred and seventy-five days from the first, the opening into the chest remained 
open. Then followed five months of comparative good bealth, the opening into the chest being closed, and he able to attend to his work.

In a few days less than a year from his first attack, the side opened spontaneonsly at the place where the original opening had been made. Ever after this he lost flesh and strength, and the side remained permanently open, excepting about five weeks.

At the end of fourteen months he began to develop pyamic abscesses, of which five, at least, were opened, one communicating with the pus-cavity in the iliac fossa, and this, in turn, with the pleural cavity. He died of exhaustion, hastened, perhaps, a few moments by my endeavor to make him more comfortable, in one year, six months, and twenty-four days from his first attack in March, 1886.

One point of interest is the canse of the pnenmothorax; if, as $I$ have alrearly intimated, a rent in the pleura and lung was caused by the coughing and strangling, and through this rent air entered the pleural cavity, it may be looked upon as traumatic, and liable to occur at any time. On the other hand, if the rent in the lung was cansed by the nature of the plearitis or the character of the contained flnid, it renders the case more open to speculation.

We take it for granted and self-evident that pneumothorax is a secondary affection, inasmuch as there must have been severe injury or lesion to the pleura to allow of air entering the pleural cavity.

Pneumothorax, pure and simple, is but rarely met with, except for a short time, or in connection with fluid. This condition was recognized as long ago as the time of Hippocrates, and the physical sign caused thereby, namely, succussion, is often designated the Hippocratic sign.

Laennec divided pneumothorax into three varieties: First, essential pneumothorax results from spontaneous formation of gas in the pleural cavity ; second, pneumothorax from purulent decomposition of the liquids effused into the pleuræ; third, pneumothorax from perforation due to rupture of the pleura, or to an accidental opening by which atmospheric air or gas from the lungs is introduced into the pleural cavity.

Notwithstanding this distinguished authority, it has been satisfactorily demonstrated that the pleuræ cannot secrete air or gas. As to the second variety, namely, the decomposition of the effused fluid, althongh at one time supported by snch inen as Hnghes Bennett, Townsend, Wonderlich, and Jaccond, it is difficult to understand how this can be, as the presence of air is the sine qua non of decomposition.

We are, therefore, left to accept the third variety ; namely, the perforation of lung tissue. 'This may be traumatic, or it may be due to a pathological process going on in the lungs, pleuræ, or some adjacent organ.

That pneumothorax is not an infrequent occurrence in phthisis pulmonalis, all will agree. This not only from our own individual experience, but all observers state that phthisis is by far the most frequent cause of pneumothorax; Walshe says ninety per cent. Fernet ${ }^{2}$ states that pneumothorax results in nine-tenths of the cases from some of the forms of pulmonary phthisis. Fraentzel ${ }^{3}$ says, from his own observation, that 90 out of 96 cases of pneumothorax are produced by vomica on the surface of the lung in the course of caseous pneumonia.

\footnotetext{
2 Nouveau Dict., Vol. xxviii.
}

Ziem. Cyc., Vol. iv.
Lansier shows, in his frequently quoted table, the relative frequency of the principal causes of pneumothorax in 131 cases:

$$
\begin{aligned}
& \text { Proumothorax with phthisis } \quad \cdot \quad \cdot \quad \cdot \quad \cdot \quad \cdot \quad 81 .
\end{aligned}
$$

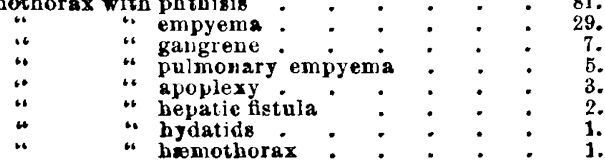

Here empyema takes second rank, which seems to be in keeping with common experience.

If this be the canse in the case I have reported, that is, if mine was a case of purnlent pleuritis before the introduction of air, then it is not a particularly rare case. On the other hand, if it was a case of simple acute pleurisy with effusion, and the early introduction of air by traumatism or otherwise, then it may be classed as an unusual case.

Concerning the last illness, which may be considered as a sequence of the first, one is curious to know whether the termination would have been different had he not been a victim of spinal curvature; in other words, how much did the curvature of the spine contribute to the fatal termination. I regret that the vertebræ were not removed or examined more carefully in situ. Certainly, the point of curvature was and had been bathed probably in or covered by a pussecreting surface for more than a year.

The tissues over the vertebra, as well as the inflammatory products, were very easily removed, but I cannot say the bones were roughened in evidence of nccrosis. The pyogenic process having dissected off the at tachments of the diaphragm to the spine, the descent to the pelvis behind the peritoneum was easy. Certainly, the route from the bronchi and opening at the angle of the scapula to the opening near the fourth lumbar vertebra was sufficiently circuitous to be, at least, unique.

\section{A CASE OF ABSCESS OF THE CEREBELLUM FROM EAR DISEASE.}

BY J. ORNE GREEN, M.D.

Patrick F., aged thirty-six. Mother died insane, father now in Danvers Asylum, also insane. No history of syphilis. He was kicked by a horse in right temporal region fifteen years ago; some brain sy mptoms, probably concussion, from which he soon recovered. As result of this kick right auricle is adherent to scalp by cicatricial tissue. Ever since this injury has had an otorrhœa on right, moderately profuse, but unattended by pain or external swelling.

The last five months has complained much of his head, especially in right temporal region. Entered Bost on City Hospital, service of Dr. Sumner, in March, 1888 , with partial paresis of all branches of right facial nerve of only a few days' duration, with head-ache referred to right temporal region; vomited more or less daily, especially at night, and apparently without cause. Intellect perfectly clear, appetite poor, bowels not constipated. Physical examination revealed nothing except the paresis of right facial, and the otorrhœa. The paresis entirely disappeared without treatment in four days.

I saw him on March 17th, and found the right meatus completely filled by polypoid growths, and the ${ }_{23}^{1}$ Read before the Boston Society for Medical Improvement, April 